\title{
Direct Visualization of Structures of Atmospheric Corrosion Products on the Steel Surfaces by Two-dimensionally X-ray Absorption Fine Structure
}

\author{
Takuya MORI, ${ }^{1 * *}$ Takahiro OZAWA, ${ }^{2)}$ Yuki HIRUTA, ${ }^{1)}$ Seigo MATSUNAGA, ${ }^{1)}$ Kazunori FUKUDA ${ }^{1)}$ and \\ Amane KITAHARA ${ }^{1)}$ \\ 1) Kobelco Research Institute Inc., 1-5-5, Takatsukadai, Nishi-ku, Kobe, 651-2271 Japan. \\ 2) Kobe Steel, Ltd., Surface Design and Corrosion Research Section, Materials Research Laboratory, 1-5-5, Takatsukadai, \\ Nishi-ku, Kobe, 651-2271 Japan.
}

(Received on August 31, 2021; accepted on November 29, 2021; J-STAGE Advance published date: February 5, 2022)

\begin{abstract}
In this study, using two-dimensional X-ray absorption fine structure (2D-XAFS), the structures of atmospheric corrosion products on the steel surfaces were observed in the cross-sectional direction. For 2D-XAFS measurement, the sample was sliced from the surface of the rust toward the substrate using a microtome and thinned below $10 \mu \mathrm{m}$. In addition, the 2D-XAFS data incorporated an unsupervised learning denoising method based on the Noise2Noise algorithm for achieving high spatial resolutions. The results demonstrate that the structure of the amorphous rust exhibits an $\alpha$-FeOOH-like structure, and the analysis of the composition ratio of $\mathrm{Fe}_{3} \mathrm{O}_{4}, \alpha-\mathrm{FeOOH}$, and $\gamma \mathrm{FeOOH}$ revealed the distribution the $\mathrm{Fe}_{3} \mathrm{O}_{4}$ ratio. This distribution provided compelling evidence for proceedings of the reactions suggested by Evans et al. during the atmospheric exposure test.
\end{abstract}

KEY WORDS: Noise2Noise; two-dimensional X-ray absorption fine structure; micro-ordered slicing; atmospheric corrosion.

\section{Introduction}

Corrosion can destroy several structural products and costs approximately US\$2.5 trillion, which is equivalent to $3.4 \%$ of the global Gross Domestic Product (GDP) (2013). ${ }^{1)}$ To date, significant developments and improvements in corrosion-resistant alloy steels and corrosion mitigation methods, respectively, have been realized worldwide.

Physicochemical analytical techniques, which are used for the characterization of rust layer and corrosion products, are significantly important for the clarification of the mechanisms of surface protection properties of industrial steel products correlated with the macro/nanostructures and the composition of the rust layer. To understand the generation mechanisms of the rust, the analysis of the structure and compositions for cross-sectional directions is important. The cross-sectional macrostructure of rust layers on the steel has been observed by scanning electron microscopy with energy dispersive X-ray micro analysis (SEM-EDX), and electron prove micro analysis (EPMA). ${ }^{2,3)}$ These techniques observed morphology of rust layers on steel with

\footnotetext{
* Corresponding author: E-mail: mori.takuya@kki.kobelco.com
}

high spatial resolutions. Moreover, they can be analyzed the elemental distributions in the rust layers. However, the difference of crystal structure and covalent of iron cannot be evaluated by these experiments. The knowledge of the structure of corrosion products, such as $\alpha-\mathrm{FeOOH}, \gamma-\mathrm{FeOOH}$, $\beta$ - $\mathrm{FeOOH}, \mathrm{Fe}_{2} \mathrm{O}_{3}$, and $\mathrm{Fe}_{3} \mathrm{O}_{4}$, is important to understand the surface protection properties of steel, because the chemical stability, and mechanistic properties of these compounds are difference.

X-ray diffraction (XRD) is generally used to determine the crystal structure of the corrosion products to evaluate the structural difference of the corrosion products. ${ }^{3-5)}$ However, the structures of amorphous rust and other low-crystallinity phases could not be detected by XRD. This amorphous nature makes it difficult to investigate the structure of corrosion products in the atmospheric corrosion rust. To overcome these issues, X-ray absorption fine structure (XAFS), ${ }^{6-9)}$ Mössbauer spectroscopy, ${ }^{4,10-12)}$ Infra-red spectroscopy, ${ }^{4)}$ and Raman spectroscopy ${ }^{3,13,14)}$ have been used for the analysis of the structure of the corrosion products regardless of their crystallinity. Above these experiments, XAFS analysis has a possibility of the analysis of the cross-sectional directions by using micro-beam optics ${ }^{15-18)}$ 
or multi-channel detectors ${ }^{19-21)}$ (so-called two-dimensionally XAFS(2D-XAFS)), because above other experiments need the relatively large amount of mass or long exposure times to obtain the sufficient signals. Then the visualizations of the structures of actual corrosion products on the surface of the steel were difficult. 2D-XAFS seems to be observed the macro structure of rust layers in the view of the chemical state of iron, directly.

For corrosion studies, 2D-XAFS using micro-beam was applied to the cross-section of the rust layer formed on weathering steel. ${ }^{15,18)}$ Fluorescent Fe K-edge XAFS spectra were obtained with a spatial resolution of approximately 3 $\mu \mathrm{m}$. Moreover, X-ray fluorescence analysis was performed, and the relationship between the crystal structure of the rust and $\mathrm{Cr}$ concentration was established. However, the detailed structure of corrosion products on steel surfaces has not been clarified till date.

In this study, 2D-XAFS using camera detector were applied for the directly visualizations of structures of the corrosion products on steel surfaces. Atmospheric corrosion steels were chosen for the analysis target in our study. Under atmospheric conditions, the rust layers comprised $\alpha$-FeOOH, $\gamma$-FeOOH, $\beta$-FeOOH, $\mathrm{Fe}_{3} \mathrm{O}_{4}$, and amorphous rust. ${ }^{2)}$ The chemical state of amorphous rust, and $\mathrm{Fe}_{3} \mathrm{O}_{4}$ is evaluated by $2 \mathrm{D}$-XAFS. In our approach, the transmission mode for the XAFS experiments against the cross-section of the corrosion steel was performed using a micro-slicing sample. The transmission XAFS spectrum, which was not affected by self-absorption, can be analyzed by the sum of the weighted standard spectrum. Moreover, the spatial resolution of 2D-XAFS was improved by using the denoised treatment based on unsupervised learning methods.

\section{Experimental}

\subsection{Sample Preparation}

$\mathrm{Fe}-0.5 \mathrm{mass} \% \mathrm{C}$ alloy substrate exposed to atmospheric conditions for 6 months at CHOSHI EXPOSURE TEST AND RESEARCH CENTER (Japan Weathering Test Center) was used in this study. The testing conditions were based on JIS Z 2381. ${ }^{22)}$ The testing area was directed in the south direction, and the tilting angle was set to $45^{\circ}$. The corrosion products on the exposed samples were estimated using XRD measurements.

\subsection{XAFS Measurements}

2D-XAFS experiments were performed at BL16B2 of SPring-8 (Hyogo, Japan). The optics of this experiments are shown in Fig. 1. The Fe K-edge XAFS spectra, at the energy range of $7170-7655 \mathrm{eV}$, were measured in transmission mode using a Xsight ${ }^{\mathrm{TM}}$ micron LC camera (Rigaku, Japan) with a 2048 pixel $\times 2$ 048-pixel sCMOS detector, and the incident X-ray beam was monochromated by a $\mathrm{Si}$ (111) crystal. A $1.3 \times 1.3 \mathrm{~mm}^{2}$ field of view was captured with a pixel size of $0.65 \mu \mathrm{m}$. The beam size was set to $0.7 \times$ $1.3 \mathrm{~mm}^{2}$ (about $1100 \times 2048$ pixels in camera detector), and the exposure time was set about $73 \mathrm{~min}$./spectrum. The central granting angle of the $\mathrm{Rh}$ coated Silicon planar mirror was $5 \mathrm{mrad}$ to alleviate the effect of higher-order light.

\subsection{Data Analysis}

A specific area (256 pixel $\times 256$ pixel) was analyzed. Python programming language was selected for software development to analyze 2D-XAFS data. Noise2noise trained model was used as the network architecture for denoising ${ }^{23}$ Sparseness parameter of the L2 norm was selected as 0.01 . The input images were represented in the range $[-0.5$, $0.5]$. The treatment of the background subtraction and normalization was performed using the Larch 0.9 .47 library. ${ }^{24)}$ The experimentally obtained XAFS spectrum fit the curve obtained by the weighted addition of the spectra for $\mathrm{Fe}_{3} \mathrm{O}_{4}$, $\alpha-\mathrm{FeOOH}$, and $\gamma-\mathrm{FeOOH}$. Fitting was also performed using Larch 0.9.47 library. $^{24)}$ The chemical composition ratio of these components and reduced chi-square (below $\chi^{2}{ }_{v}$ ) values were reconstructed in the image.

$\chi^{2}{ }_{v}$ values were determined below equations: ${ }^{25)}$

$$
\chi_{v}{ }^{2}=\chi^{2} /\left(\mathrm{N}-\mathrm{N}_{\text {varys }}\right)
$$

$\chi^{2}$ is the residual sum of squares, $\mathrm{N}$ is the number of data, and $\mathrm{N}_{\text {varys }}$ is the number of variables.

This value was used for the index of the good fittings of spectrum.

\section{Results and Discussion}

XRD patterns of powders scraped from the surface of the sample are shown in Fig. 2. Peaks corresponding to $\alpha-\mathrm{FeOOH}$ and $\gamma-\mathrm{FeOOH}$ are observed. The peak intensity of $\gamma-\mathrm{FeOOH}$ is larger than that of $\alpha-\mathrm{FeOOH}$, and it is the main crystalline phase in the rust layer. Peaks corresponding to $\mathrm{Fe}_{3} \mathrm{O}_{4}$ are not observed (overlapping with the peaks of $\alpha-\mathrm{FeOOH}$ and $\gamma-\mathrm{FeOOH}$ ), then the crystalline $\mathrm{Fe}_{3} \mathrm{O}_{4}$ phase was not included in the rust layer of this sample.

For 2D-XAFS measurements, the obtained corrosive samples were embedded in epoxy resin and sliced from the surface of the rust toward the substrate (thickness $<10 \mu \mathrm{m}$ ) using a microtome. A photograph of the sliced sample is shown in Fig. 3. The rust layers were confirmed on the top

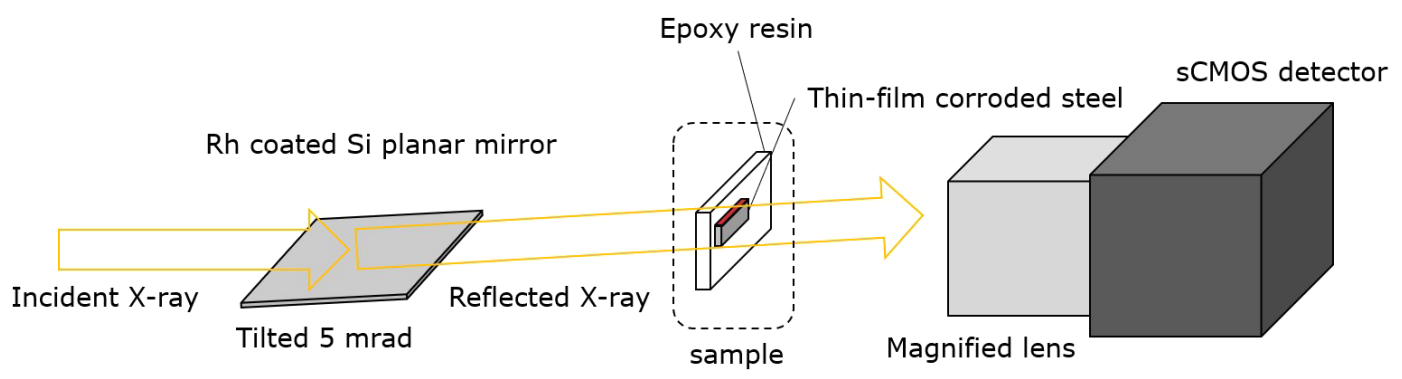

Fig. 1. The schematic diagrams of experimental configurations of imaging-XAFS. (Online version in color.) 


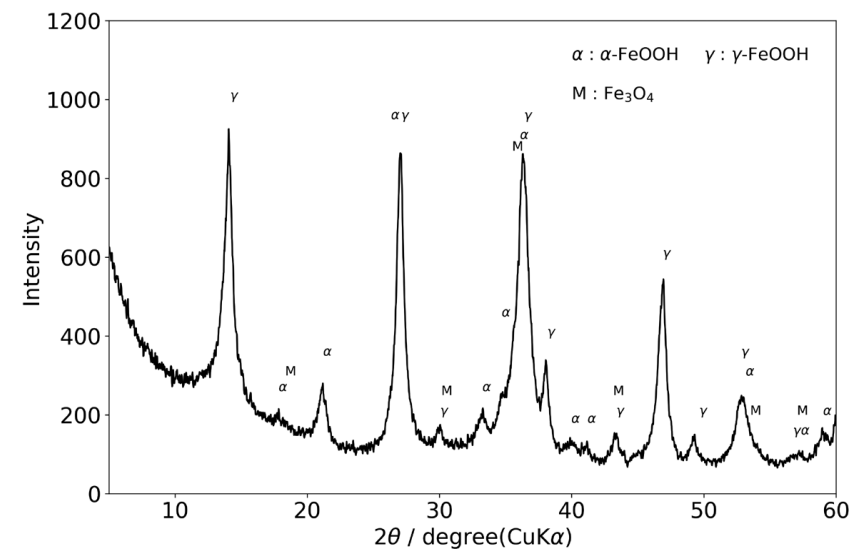

Fig. 2. XRD patterns of the powders scrapped off from surface of corrosion steel.

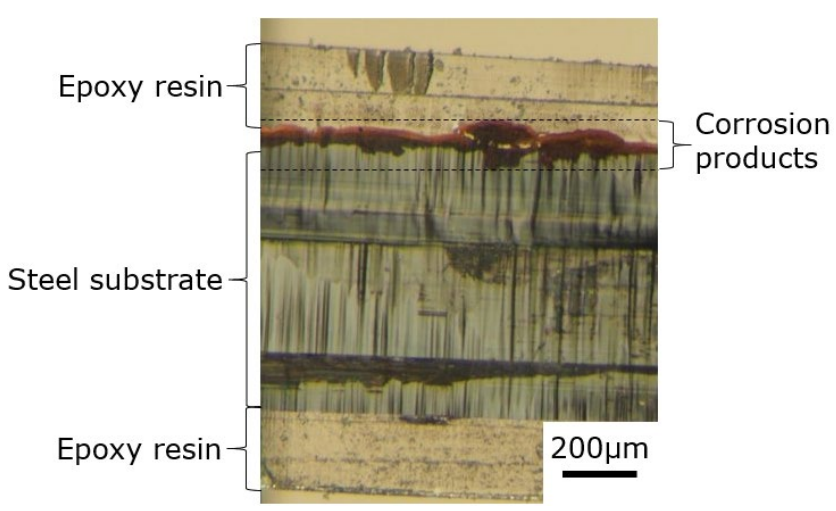

Fig. 3. Optical microscopy image of the cross-section of the sliced corrosion steel. (Online version in color.) of the steel substrate, and rust were not peeled off from the steel substrate after slicing.

The spatial resolutions of $2 \mathrm{D}-\mathrm{XAFS}$ did not correspond with the pixel resolutions because the spreading of the fluorescent screen and the diffusion of the X-ray beam reduced the signal-to-noise ratio. Typically, the $\mathrm{x} \times \mathrm{x}(\mathrm{x}=2,3$, $4 \ldots)$ pixels of the detector are averaged. In our approach, denoising treatment based on Noise2Noise algorithm ${ }^{23)}$ was applied for a few hundred image datasets of 2D-XAFS to decrease the noise at each energy. Figures 4(a) and 4(b) show the results of the original picture compared with the denoised picture, respectively. The magnified pictures were also shown in Figs. 4(c) and 4(d). Although the adjacent pixels were smeared out, the contour of the rust and steel were remained.

Generally, the denoised character was evaluated the values of the peaks of signal and noise ratio (PSNR). ${ }^{23)}$ To evaluate the PSNR, the true image or signal were needed. However, the true signal, which includes zero noise, cannot be obtained. In this study, the denoising character was evaluated using the histogram of the background signal of the picture. If the data are noisy, the background signal is distributed. The normalized histograms of the background signal are shown in Fig. 4(e). The histogram shape of the denoised data was very sharp, and the standard deviation value of the denoised data was 0.006 . This value is reduced to $1 / 5$ of that of the original picture $(0.03)$. Then, the distributions of background intensity of the denoised image were lower than those of the original image. It is indicated that the background noise of each pictures decreased. The obtained spectra as XAFS, extended x-ray absorption fine (a)

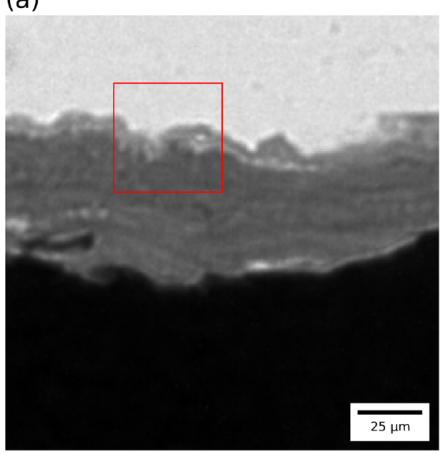

(c)

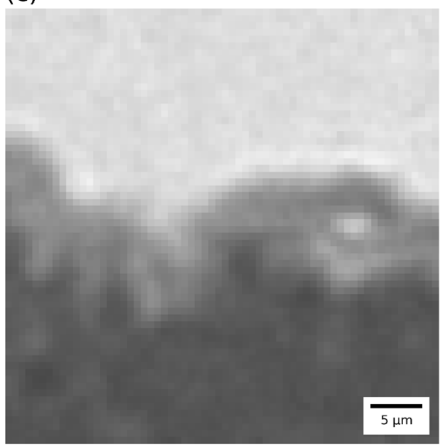

(b)

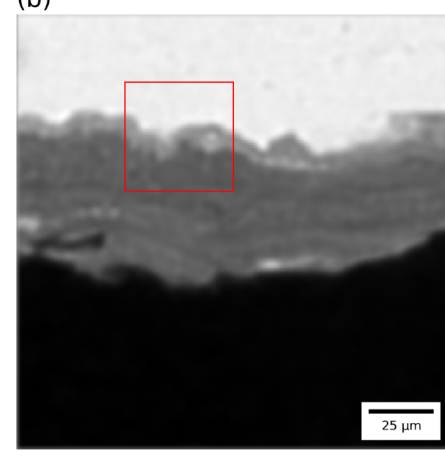

(d)

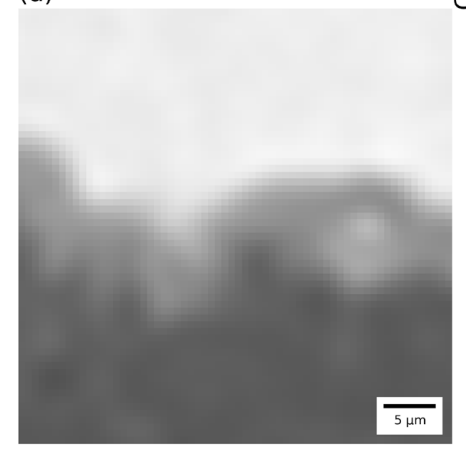

(e)

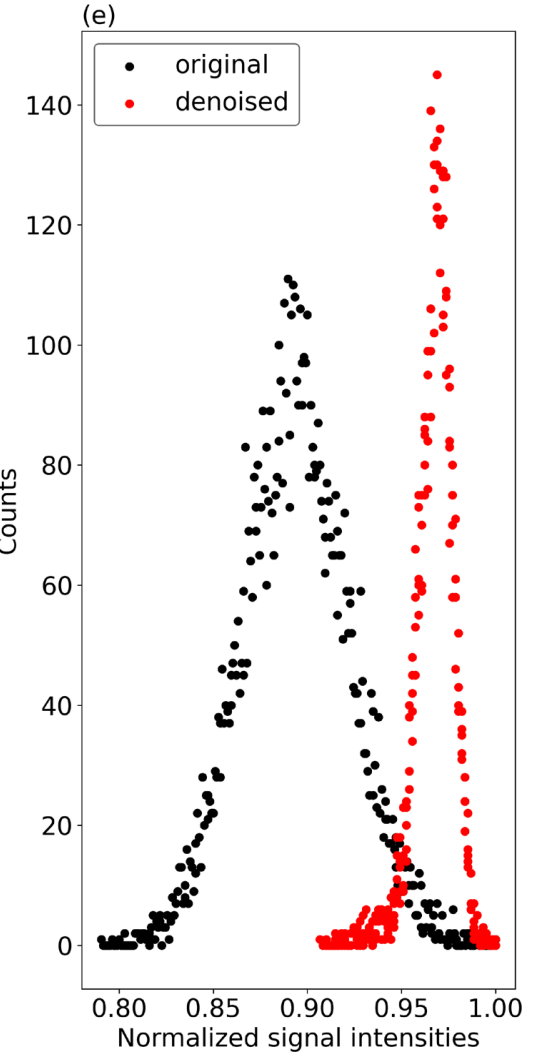

Fig. 4. X-ray transmission image of the cross-section of the sliced corrosion steel of the (a) original data, (b) denoised data, (c) enlarged figure of red squared region in (a), (d) and enlarged figure of red squared region in (b) (e) Histogram of the background signal of the original data (black) and denoised data (red). (Online version in color.) 
structure (EXAFS) oscillations, and Fourier transform of EXAFS oscillations from $1 \times 1$ pixel is shown in Figs. 5(a), $5(\mathrm{~b})$, and 5(c), respectively. The spectrum noise is clearly reduced. For analysis of the structure of corrosion products, XAFS spectrum were obtained from $1 \times 1$ pixel $\left(0.65 \mu \mathrm{m}^{2}\right)$ in the image datasets.

The standard spectrum using for this fitting analysis were shown in Fig. 6(a). Although $\mathrm{Fe}_{3} \mathrm{O}_{4}$ was not observed in the XRD patterns, we considered $\mathrm{Fe}_{3} \mathrm{O}_{4}$ as a component of the 2D-XAFS analysis. For example, the fitted results of the XAFS spectra of a specific point in the rust layer by the three components are shown in Fig. 6(b). The fitting results and experimental data are very similar. Here, $\chi^{2}{ }_{v}$ is approximately 0.0006 . The border values of the fitting results explained by the three components were set to 0.001 . The compositions of the three components obtained by spectrum fitting are shown in Figs. 7(a), 7(b), and 7(c), respectively. The analysis regions of the fittings are only rust layers. Moreover, the $\chi^{2}{ }_{v}$ values as the index of the good fitting are also shown in Fig. 7(d). The blue regions in Fig. 7(d) were fitting were relatively good regions, Then, these regions mainly comprise $\mathrm{Fe}_{3} \mathrm{O}_{4}, \alpha$-FeOOH, and $\gamma$-FeOOH. Here,
$\mathrm{Fe}_{3} \mathrm{O}_{4}$ was confirmed in the XAFS measurements, although it was not confirmed by the XRD measurements of the powder scraped from the surface of the corrosion steel. Thus, the $\mathrm{Fe}_{3} \mathrm{O}_{4}$ phase would have an amorphous nature. The $\chi^{2}{ }_{v}$ values at the interface between the steel and the rust layers were very large (red regions in Fig. 7(d)). This region was mixed with steel, which was not considered in the fitting. Another red color region, such as that near the surface of the rust, may include a spectrum with a bad signal-to-noise ratio because the mass of the corrosion products in the penetration direction of the X-ray was not sufficient to measure the good XAFS spectrum.

The composition ratios of the ferric oxyhydroxides, $\alpha-\mathrm{FeOOH}$ and $\gamma-\mathrm{FeOOH}$, in the rust layer are shown in Figs. 7(a) and 7(b), respectively. $\alpha-\mathrm{FeOOH}$ was detected at nearly the same ratio as that for $\gamma-\mathrm{FeOOH}$, although some crystalline $\alpha$-FeOOH was also detected. The hydrated ferrous ions initially formed during corrosion and then airoxidized into the solid precipitate of ferric hydroxide. The ferric hydroxide was dehydrated and formed into a mass of ferric oxyhydroxide, FeOOH. Under atmospheric conditions, the generated ferrous ions precipitated to $\gamma-\mathrm{FeOOH}$
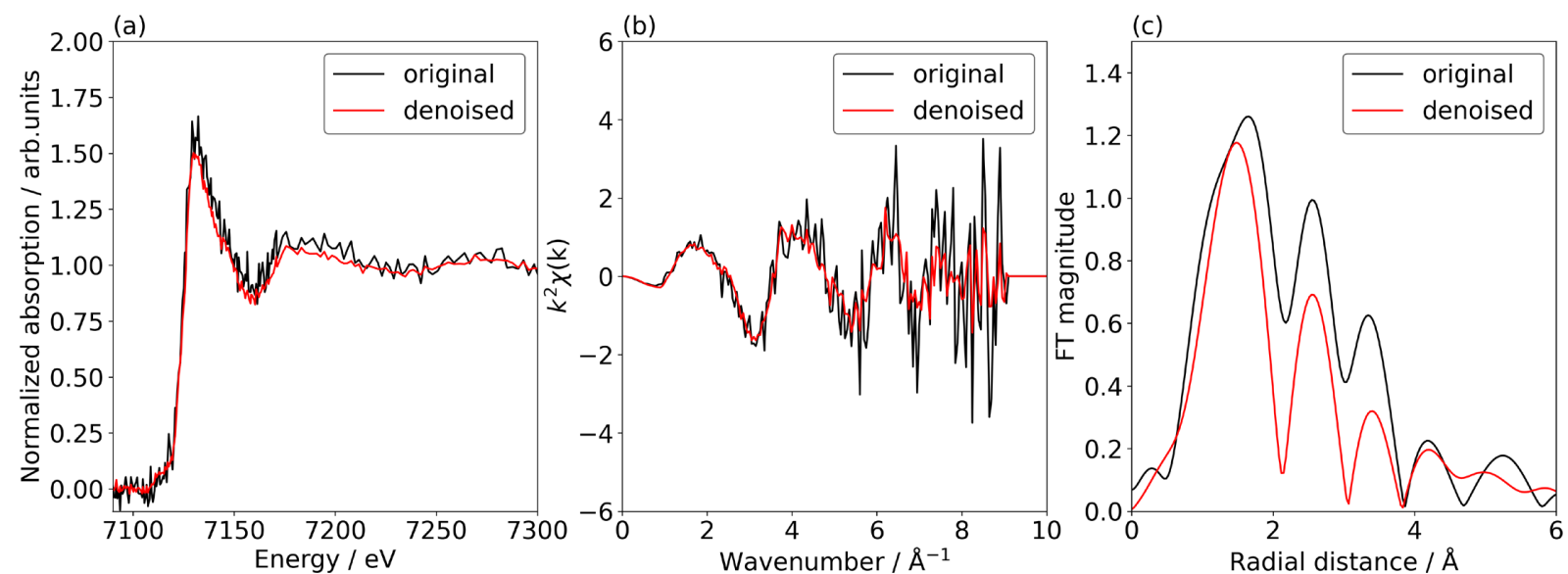

Fig. 5. (a) Fe K-edge XAFS, (b) EXAFS oscillations, and (c) Fourier transforms of EXAFS of the original data (black) and denoised data (red). (Online version in color.)
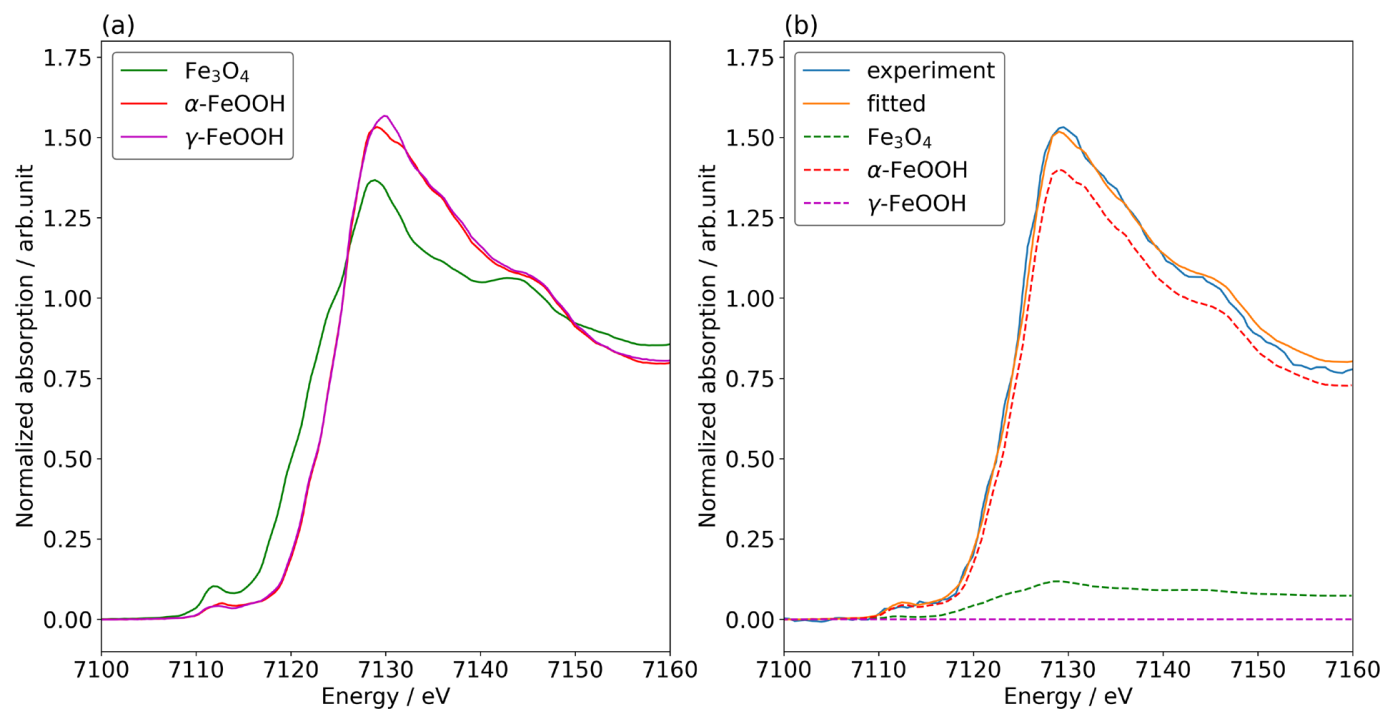

Fig. 6. Fe K-edge XAFS spectra (a) standard spectrum of $\alpha$-FeOOH, $\gamma$-FeOOH, and $\mathrm{Fe}_{3} \mathrm{O}_{4}$, and (b) example of fitted curve obtained by the weighted addition of spectrum for $\alpha-\mathrm{FeOOH}, \gamma-\mathrm{FeOOH}$, and $\mathrm{Fe}_{3} \mathrm{O}_{4}$. (Online version in color.) 


\section{(a)}

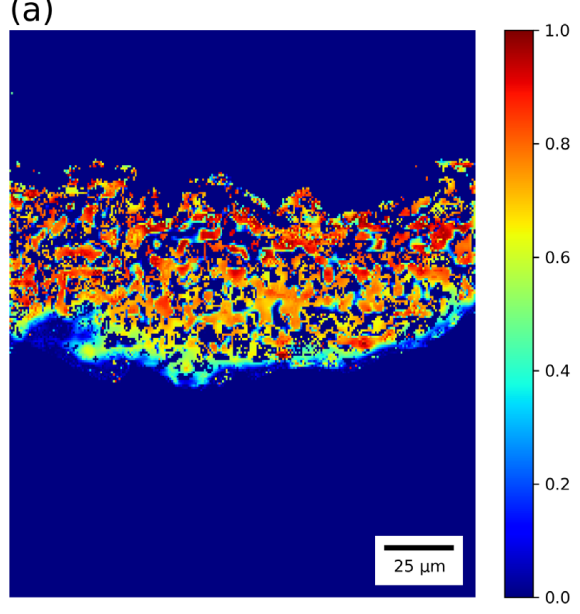

(c)

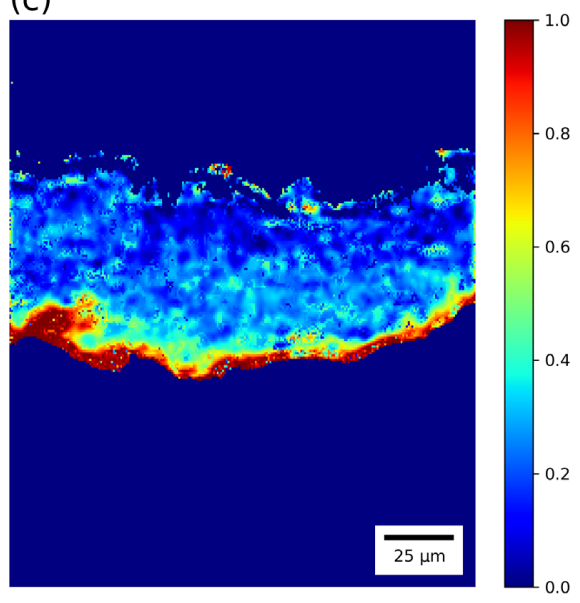

(b)

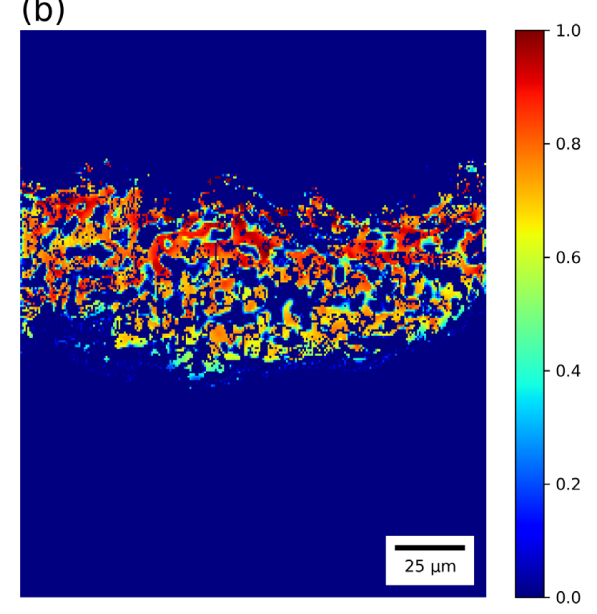

(d)

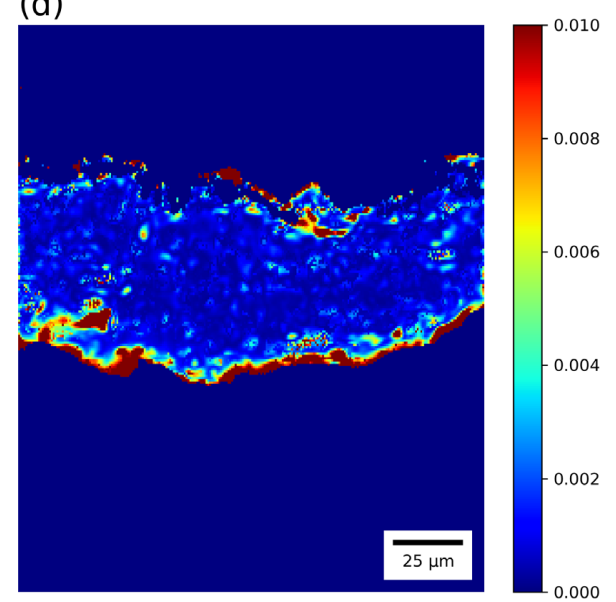

Fig. 7. Component ratio maps of the sliced corrosion steel via XAFS measurements (a) $\alpha$-FeOOH, (b) $\gamma-\mathrm{FeOOH}$, (c) $\mathrm{Fe}_{3} \mathrm{O}_{4}$, and (d) $\chi^{2}$. (Online version in color.)

or amorphous-rust $\mathrm{t}^{2,3,26,27)}$ because the acidity of the steel surface was generally neutral or mildly acidic. It is therefore speculated that the precipitated amorphous rust had an $\alpha$-FeOOH-like structure.

Comparing Figs. 7(a) and 7(b) shows that the missing parts of $\gamma-\mathrm{FeOOH}$ were transformed to $\alpha-\mathrm{FeOOH}$. It is known from a previous study that $\gamma$-FeOOH was dissolved in moist conditions, and ferric ions precipitated as amorphous rust and aged to form $\alpha-\mathrm{FeOOH} .^{2,27)}$ This transformation occurred relatively easily during the continuous wet and dry cycling ${ }^{26)}$ Moreover, as noted above, amorphous rust had an $\alpha$-FeOOH-like structure. This suggests that $\gamma$-FeOOH was partially dissolved and transformed into amorphous rust and/or $\alpha$-FeOOH.

The composition ratio of $\mathrm{Fe}_{3} \mathrm{O}_{4}$ in the rust layer is shown in Fig. 7(c). $\mathrm{Fe}_{3} \mathrm{O}_{4}$ co-existed with the ferric oxyhydroxides, and the ratio of $\mathrm{Fe}_{3} \mathrm{O}_{4}$ increased around the steel. Under atmospheric conditions, the corrosive reaction proceeded through the wet and dry cycles. Evans et al. proposed the following reactions: ${ }^{28,29)}$

Wet condition:

$$
\mathrm{Fe} \rightarrow \mathrm{Fe}^{2+}+2 \mathrm{e}^{-}
$$

$$
8 \mathrm{FeOOH}+\mathrm{Fe}^{2+}+2 \mathrm{e}^{-} \rightarrow 3 \mathrm{Fe}_{3} \mathrm{O}_{4}+4 \mathrm{H}_{2} \mathrm{O}
$$

Dry condition:

$$
\begin{gathered}
4 \mathrm{Fe}_{3} \mathrm{O}_{4}+8 \mathrm{H}_{2} \mathrm{O} \rightarrow 12 \mathrm{FeOOH}+4 \mathrm{H}^{+}+4 \mathrm{e}^{-} \\
\mathrm{O}_{2}+2 \mathrm{H}_{2} \mathrm{O}+4 \mathrm{H}^{+}+4 \mathrm{e}^{-} \rightarrow 4 \mathrm{H}_{2} \mathrm{O} \ldots \ldots \ldots . . .
\end{gathered}
$$

In the wet condition, the closer to the steel, the higher the concentrations of dissolved ferrous ions. Then, the dissolution of iron in the wet condition easily occurred near the steel, and dissolved ferrous ions reacted with ferric oxyhydroxide to produce $\mathrm{Fe}_{3} \mathrm{O}_{4}$. (Eqs. (2) and (3)) Moreover, the $\mathrm{Fe}_{3} \mathrm{O}_{4}$ around the surface of rust reacted with water and oxygen and retransformed ferric oxyhydroxide under dry conditions (Eqs. (4) and (5)). Then, the ratio of $\mathrm{Fe}_{3} \mathrm{O}_{4}$ around the surface of rust decreased, as shown in Fig. 7(c). Hence, Fig. 7(c) clearly shows to proceed the Evans model reaction during the exposure test. The cross-sectional gradient of concentrations of $\mathrm{Fe}_{3} \mathrm{O}_{4}$ in the rust layer was firstly confirmed in our approach.

\section{Conclusions}

The structures and composition ratios of $\mathrm{Fe}_{3} \mathrm{O}_{4}, \alpha-\mathrm{FeOOH}$, and $\gamma$-FeOOH regardless of their crystallinity were directly visualized via $2 \mathrm{D}$-XAFS measurements against a microtome sliced sample. The distributions of the corrosion products in rust layer were directly visualized at the first time. It was 
observed that the structure of the amorphous rust had an $\alpha$-FeOOH-like structure. Moreover, the gradient of concentrations of $\mathrm{Fe}_{3} \mathrm{O}_{4}$ in the rust layer indicated that the ferrous ions were dissolved from the steel and formed in $\mathrm{Fe}_{3} \mathrm{O}_{4}$ because of the reaction with ferric oxyhydroxide. These reactions were proposed by Evans et al. Our results firstly detected the cross-sectional gradient of the concentrations of $\mathrm{Fe}_{3} \mathrm{O}_{4}$ and provide direct evidence for the occurrence of the Evans model reaction during the atmospheric corrosion.

The sliced sampling and 2D-XAFS treated by the Noise2Noise algorithm are powerful tools to investigate the cross-sectional macroscopic structure of the corrosion products regardless of their crystallinity. However, weight calculations of the standard spectrum were required for the detailed analysis of this experiment. When the comprised compounds in the rust layer was unknown, the obtained spectrum could not be analyzed, and visualized the structure. The database of the XAFS spectrum ${ }^{30,31)}$ of the estimated corrosion products is required to analyze the complex corrosion compounds on the several steel.

\section{Acknowledgement}

2D-XAFS experiments were performed at beam lines BL16B2 of SPring-8 with the approval of the Japan Synchrotron Radiation Research Institute (JASRI) (proposal No. 2020A5320).

\section{REFERENCES}

1) G. Koch, J. Varney, N. Thompson, O. Moghissi, M. Gould and J. Payer: Int. Measures of Prevention Application, and Economics of Corrosion Technologies Study, NACE International, (2016), http:// impact.nace.org/economic-impact.aspx, (accessed 2021-08-26).

2) T. Misawa: Zairyo-to-Kankyo, 50 (2001), 538 (in Japanese).

3) T. Misawa, M. Yamashita, Y. Matsuda, H. Miyuki and H. Nagano: Tetsu-to-Hagané, 79 (1993), 69 (in Japanese). https://doi.org/10.2355/ tetsutohagane1955.79.1_69

4) R. Balasubramaniam and A. V. Ramesh Kumar: Corros. Sci., 42 (2000), 2085. https://doi.org/10.1016/S0010-938X(00)00045-7

5) S. Hara, M. Yamashita, T. Kamimura and M. Sato: J. Jpn. Inst. Met., 71 (2007), 346 (in Japanese). https://doi.org/10.2320/jinstmet.71.346

6) T. Ozawa, S. Yamamoto, T. Mori, M. Yokomizo, L. Li, K. Yokoyama and T. Haruna: Zairyo-to-Kankyo, 69 (2020), 73 (in Japanese). https://doi.org/10.3323/jcorr.69.73
7) M. Kimura, M. Kaneko and N. Ohta: ISIJ Int., 42 (2002), 1399. https://doi.org/10.2355/isijinternational.42.1399

8) M. Kimura, T. Suzuki, G. Shigesato, H. Kihira and S. Suzuki: ISIJ Int., 42 (2002), 1534. https://doi.org/10.2355/isijinternational.42.1534

9) T. Nakayama: Zairyo-to-Kankyo, 64 (2015), 273 (in Japanese). https://doi.org/10.3323/jcorr.64.273

10) S. Nasu: Zairyo-to-Kankyo, 54 (2005), 45 (in Japanese). https://doi. org/10.3323/jcorr 1991.54 .45

11) A. Vértes and I. Czakó-Nagy: Electrochim. Acta, 34 (1989), 721. https://doi.org/10.1016/0013-4686(89)87106-3

12) D. C. Cook: Corros. Sci., 47 (2005), 2550. https://doi.org/10.1016/j. corsci.2004.10.018

13) M. Yamashita, H. Nagano, T. Misawa and H. E. Townsend: ISIJ Int., 38 (1998), 285. https://doi.org/10.2355/isijinternational.38.285

14) M. Yamashita, H. Miyuki, H. Nagano and T. Misawa: Tetsu-toHagané, 83 (1997), 448 (in Japanese). https://doi.org/10.2355/ tetsutohagane1955.83.7 448

15) M. Nagoshi, T. Kawan̄o, I. Kage and S. Hayakawa: ISIJ Int., 51 (2011), 93. https://doi.org/10.2355/isijinternational.51.93

16) S. Endo, Y. Terada, Y. Kato and I. Nakai: Environ. Sci. Technol., 42 (2008), 7152.

17) M. Nagoshi, T. Aoyama, Y. Tanaka, T. Ishida, S. Kinoshiro and K. Kobayashi: ISIJ Int., 53 (2013), 2197. https://doi.org/10.2355/ isijinternational.53.2197

18) S. Hayakawa: J. Surf. Sci. Soc. Jpn., 35 (2014), 146 (in Japanese). https://doi.org/10.1380/jsssj.35.146

19) M. Mizusawa and K. Sakurai: J. Synchrotron Radiat., 11 (2004), 209.

20) J.-D. Grunwaldt, S. Hannemann, C. G. Schroer and A. Baiker: J. Phys. Chem. B, 110 (2006), 8674.

21) M. Katayama, K. Sumiwaka, K. Hayashi, K. Ozutsumi, T. Ohta and Y. Inada: J. Synchrotron Radiat., 19 (2012), 717.

22) JIS Z 2381: 2017, General requirements for atmospheric exposure testing (in Japanese).

23) J. Lehtinen, J. Munkberg, J. Hasselgren, S. Laine, T. Karras, M. Aittala and T. Aila: Proc. 35th Int. Conf. on Machine Learning (ICML 2018), ICML, San Diego, CA, (2018), 2965.

24) M. Newville: J. Phys. Conf. Ser., 430 (2013), 012007. https://doi. org/10.1088/1742-6596/430/1/012007

25) Matthew Newville, Till Stensitzki, Renee Otten and others: NonLinear Least-Squares Minimization and Curve-Fitting for Python, https://lmfit.github.io/lmfit-py/, (accessed 2021-10-28).

26) T. Misawa, K. Hashimoto and S. Shimodaira: Corros. Eng. (Jpn.), 23 (1974), 17 (in Japanese).

27) T. Misawa, K. Asami, K. Hashimoto and S. Shimodaira: Corros. Sci., 14 (1974), 279.

28) U. R. Evans and C. A. J. Taylor: Corros. Sci., 12 (1972), 227. https:// doi.org/10.1016/S0010-938X(72)90671-3

29) U.R. Evans: Nature, 206(1965), 980.https://doi.org/10.1038/206980a0

30) C. Zheng, K. Mathew, C. Chen, Y. Chen, H. Tang, A. Dozier, J. J. Kas, F. D. Vila, J. J. Rehr, L. F. J. Piper, K. A. Persson and S. P. Ong: npj Comput. Mater., 4 (2018), 12. https://doi.org/10.1038/ s41524-018-0067-x

31) S. B. Torrisi, M. R. Carbone, B. A. Rohr, J. H. Montoya, Y. Ha, J. Yano, S. K. Suram and L. Hung: npj Comput. Mater., 6 (2020), 109. https://doi.org/10.1038/s41524-020-00376-6 